\title{
A IMPORTÂNCIA DOS PIPES NA GERAÇÃO E NO COMPORTAMENTO DOS FLUXOS EM PEQUENOS CANAIS FLUVIAIS
}

\author{
Antonio Paulo Faria \\ Laboratório de Geomorfologia Fluvial, Costeira e Submarina - Departamento de Geografia - UFRJ \\ shaynie@ax.apc.org
}

\section{RESUMO}

Os canais de $1^{a}$ ordem possuem diversos aspectos singulares, como por exemplo, a sua origem em nascentes e a forma do crescimento cumulativo do fluxo na direção de jusante. A contribuição de água para o fluxo varia muito entre a nascente e a foz, de acordo com algumas características das bacias, como a geomorfologia das subunidades de encosta e aspectos ligados ao aqüifero, como capacidade de estocagem de água e a presença de pipes. Foram feitos estudos em três bacias de $1^{a}$ ordem no Maciço da Tijuca (Rio de Janeiro), para investigar a dinâmica do crescimento dos fluxos ao longo da calha e a participação dos pipes na alimentação dos canais. Os resultados obtidos mostram que em geral, da nascente até a metade da extensão do canal, a alimentação de água é de apenas $20 \%$ do total do volume do fluxo e os $80 \%$ restantes são gerados na última metade. Em períodos úmidos os pipes podem contribuir com até $58 \%$ do volume total de água para o fluxo do canal fluvial e em período seco, um único pipe pode participar com até $32 \%$. Isso mostra a importância desses dutos na dinâmica dos pequenos canais e a fragilidade das nascentes e áreas próximas, devido ao reduzido volume de vazão.

\section{INTRODUÇÃo}

Este trabalho tem como objetivo mostrar a relação dos pipes com a vazão dos canais, salientando a dinâmica de crescimento do volume dos fluxos dentro das calhas de drenagem na direção de jusante e exaltar a importância da preservação das áreas de cabeceira de drenagem. Os trabalhos foram realizados em três bacias de $1^{a}$ ordem (micro- bacias) situadas no Maciço da Tijuca (cidade do Rio de Janeiro), durante um período de dois anos, entre 1993 e 1996.

As bacias de $1^{a}$ ordem são dotadas de apenas um canal fluvial que se origina em uma nascente, de acordo com os modelos de Strahler (1952) e Shreeve (1966) e pode ser perene ou intermitente. Em clima úmido, os fluxos d'água dentro dos canais de $1^{\mathrm{a}}$ ordem crescem no sentido de jusante, ou seja, o volume de água aumenta da nascente até a foz, quando desagua em outro canal. Nessa dinâmica, os pipes (redes de dutos que drenam água no interior dos solos) exercem um papel muito importante, por contribuirem com um volume considerável de água para os fluxos dos canais.

As formas das encostas dos vales também influenciam na dinâmica de alimentação dos canais devido ao fato de que elas constituem áreas que podem concentrar ou dispersar água. Autores como Anderson e Burt (1978) denominam de hollow as áreas que formam pequenos embaciamentos nas encostas (anfiteatros), onde ocorre a convergência de água. As áreas que formam pequenos divisores de água nas encostas e que delimitam os hollows são chamadas de spur. Tsukamoto (1987) classifica os hollows como sendo bacias de zero ordem, por não terem calhas de drenagem na superfície.

Assim, segundo estes autores, os hollows devem contribuir mais para as vazões das microbacias do que as áreas de spur ou onde a encosta se encontra de forma retilínea. Desta maneira, a taxa de crescimento dos fluxos de montante para jusante depende também das características geomorfológicas das encostas das microbacias.

Pearce et al. (1986) fizeram uma revisão bibliográfica sobre os diferentes fluxos que alimentam os canais nas áreas de cabeceira 
de drenagem e mostraram o conceito de área fonte variável (variable source area). De acordo com estes autores, os fluxos são: 1) escoamento na superfície das encostas em áreas parciais, de acordo com o modelo hortoniano; 2) escoamento na superfície das encostas por saturação e 3) fluxos subsuperficiais, que ainda são divididos em fluxos rápidos em macroporos, pipes e pseudopipes e fluxos lentos, drenados por entre os microporos da matriz do solo.

Os pipes, que vêm sendo denominados no Brasil como "dutos", ou "macroporos longitudinais interligados" como sugerem Mendiondo e Tucci (1997), são canais de drenagem tubulares no interior de solos, de depósitos sedimentares e de rochas decompostas, com diâmetro variando entre poucos milímetros a mais de um metro. De acordo com Jones (1971), Beven e Germann (1982) e Mc'Caig (1983), os pipes formados no solo podem ser desenvolvidos inicialmente pelas atividades biológicas, como raízes e escavações feitas por animais e, posteriormente, os fluxos de água continuam o processo de erosão e expansão (piping). Bigarella e Mazuchowski (1985) mostram que o processo de piping também se desenvolve nos depósitos de sedimentos inconsolidados, os quais se originam pelos fluxos gerados entre camadas com permeabilidades diferentes e nas rochas cristalinas intemperizadas, nos pontos de menor resistência formados por certas estruturas. Alguns desses pipes podem atingir diâmetros superiores a 1 metro.

Nos depósitos de base de encostas rochosas, constituídos de sedimentos heterogêneos (tálus), podem ser encontrados outros tipos de pipes. A superfície impermeável formada pelos fragmentos de rocha condiciona o escoamento subsuperficial para as áreas permeáveis. Segundo Castro Jr. (1991), o material grosseiro, formado por calhaus e matacões, contido em matriz de material fino, forma caminhos preferenciais para a água gravitacional, e o fluxo erode e transporta em subsuperfície as partículas menores, como argila, silte e areia fina, produzindo redes de pipes entre os blocos rochosos. Porém, o diâmetro desses pipes varia muito no espaço, tendo poucos centíme- tros em alguns pontos e em outros podendo atingir mais de $50 \mathrm{~cm}$, de acordo com os encontrados nas bacias da área de estudo.

Jones e Crane (1984) explanam que durante as tempestades, os pipes são os responsáveis pela drenagem de cerca de $46 \%$ da água que alimenta os canais fluviais de certas microbacias, e afirmam que eles formam a maior fonte de água para os fluxos dos canais de $1^{\text {a }}$ ordem. Distinguem também pipes perenes dos pipes intermitentes e efêmeros e postulam que a rede de pipes é muito maior que o geralmente esperado. Dependendo de onde eles estão localizados, eles podem ter fluxos constantes (pipes perenes), fluxos somente durante os períodos úmidos (pipes intermitentes) ou fluxos apenas durante ou logo após as chuvas (pipes efêmeros). Os pipes perenes, com diâmetro normalmente entre 8 e $10 \mathrm{~cm}$, podem atingir mais de $330 \mathrm{~m}$ de comprimento, dependendo do diâmetro; os pipes efêmeros ou pipes alimentadores (ephemeral feeder pipes), com diâmetro médio de $5 \mathrm{~cm}$, podem atingir mais de $250 \mathrm{~m}$ de comprimento.

Mendiondo e Tucci (1997) relatam que no Rio Grande do Sul, pipes que desaguam em canais com diâmetro variando entre 2 e $12 \mathrm{~cm}$, mantém vazões por vários dias após as chuvas, que variam entre 0,092 e 0,206 litro por segundo. Dessa forma, os pipes descritos por estes autores seriam intermitentes.

De acordo com os trabalhos consultados, os pipes têm uma grande importância na dinâmica das microbacias de drenagem e baseado nessa importância, resolveu-se investigar o comportamento deles, objetivando conhecer sua dinâmica em área tropical úmida, assim como a contribuição para os fluxos dos canais de $1^{\text {a }}$ ordem. Também foi analisada a forma que os fluxos nos canais crescem na medida em que vão recebendo contribuições cumulativas de água dos fluxos subsuperficiais das encostas.

\section{ÁREA DE ESTUDO}

A área de estudo, situada no Maciço da Tijuca (Rio de Janeiro - RJ), é composta por três bacias de $1^{a}$ ordem. A primeira, denomi- 


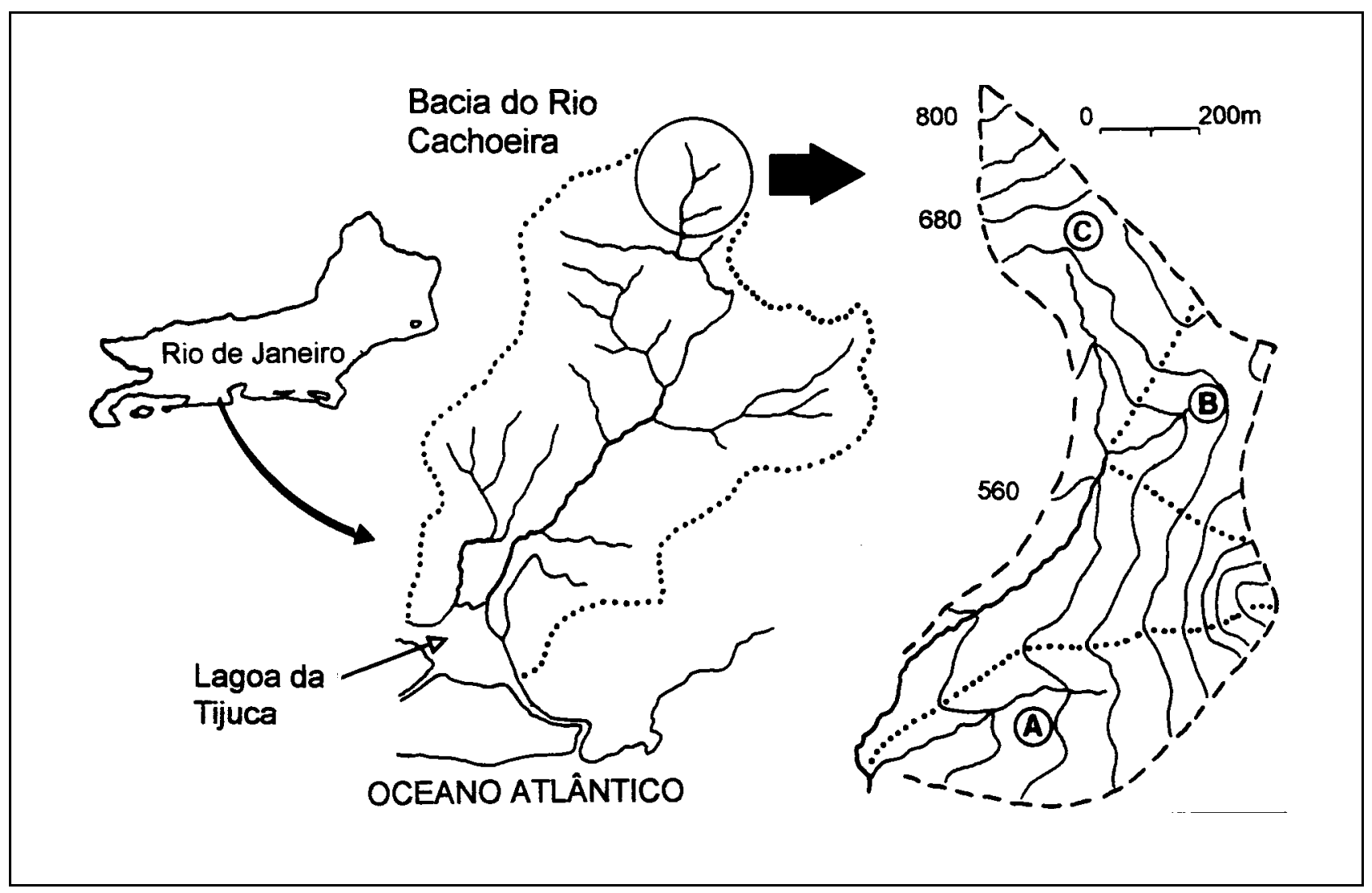

Figura 1. Área de estudo.

nada de A, possui 14 ha, a $\mathbf{B}$ tem 6 ha e a $\mathbf{C}$ com 11 ha. A litologia da área de estudo é formada por gnaisses e faixas de quartzito. As cotas altimétricas das bacias estão entre 500 e $861 \mathrm{~m}$ e as encostas possuem extensões que variam de 50 a $200 \mathrm{~m}$. As declividades predominantes estão entre 10 e $30^{\circ}$, mas parte da área ainda é constituída de paredões rochosos com declividades variando de 50 a $80^{\circ}$. As encostas com gradiente menor que $30^{\circ}$ e o fundo dos vales são cobertos por depósitos de sedimentos (tálus/colúvio). Toda a área é coberta pela floresta do tipo Tropical de Encosta e a média anual de precipitação pluviométrica é de $2.300 \mathrm{~mm}$.

\section{METODOLOGIA}

\section{Medição de vazão dos canais e dos pipes}

Para medir a vazão dos canais, foram instalados vertedouros e com recipientes de 20 litros foram medidas as descargas. Como procedimento, cronometrou-se o tempo de enchimento do recipiente, obtendo-se assim, a vazão direta em litros por segundo (l/s).

A vazão dos pipes também foi medida de forma semelhante. Foram inseridos tubos de PVC dentro dos pipes, com o diâmetro do tubo correspondendo ao do pipe, e foram utilizados recipientes de 2 litros para cronometrar o tempo de enchimento; os resultados obtidos são em litros por segundo (I/s). Alguns pipes foram mapeados e identificados pelas letras alfabéticas que caracterizam as microbacias onde estão situados, seguidas de um número de ordem (A3, B7, C2 etc.).

\section{Cálculo da taxa de crescimento do fluxo em direção de jusante}

Com a instalação de vários vertedouros em cada canal, foi possível calcular o crescimento do volume dos fluxos na direção de jusante. Os vertedouros foram distribuídos da 
seguinte forma: nas bacias A e B foram instalados 3 em cada calha, numerados de jusante para montante, porque as nascentes migram de posição nessas duas bacias; na bacia $\mathbf{C}$ foram instalados 7 vertedouros. As localizações e as distâncias entre os vertedouros podem ser observadas nas Figuras 2, 3 e 4.

Esta técnica, criada para ser aplicada aos canais de $1^{\mathrm{a}}$ ordem, deu origem à Equação (1), de acordo com Faria (1996a/1996b). O procedimento adotado foi o seguinte: a vazão de jusante é subtraída pela vazão de montante e o resultado é dividido pelo comprimento do segmento de canal entre os dois vertedouros. O resultado obtido é expresso em litro/metro/segundo. Assim foi feito para todos os segmentos de canal delimitados pelos vertedouros de cada microbacia, e com essa técnica ainda foi possível detectar os trechos entre encosta/calha que mais contribuem com fluxo de base para os canais.

$$
T c=(Q j-Q m) / L=1 / \mathrm{m} / \mathrm{s}
$$

onde $T c=$ taxa de crescimento do fluxo; $Q j=$ vazão de jusante; $Q m$ = vazão de montante e $L=$ distância entre as seções de Qj e Qm.

Também foi calculada a porcentagem de crescimento do volume do fluxo que varia da nascente até a foz do canal de primeira ordem. Na foz, a vazão foi considerada como sendo $100 \%$.

\section{ANÁLISE dOS DADOS}

\section{Crescimento dos fluxos de montante para jusante}

Os canais de $1^{a}$ ordem podem ser perenes ou intermitentes, ou uma combinação desses dois regimes. Como foi reportado anteriormente, esses canais não possuem tributários e o crescimento dos fluxos de montante para jusante se dá devido à contribuição do lençol freático, aos fluxos internos (interflow) e aos fluxos de chuvas produzidos pelo escoamento superficial nas encostas e nos canais efêmeros. Neste trabalho foi investigado apenas o comportamento dos fluxos regulares (fluxos de base), que são produzidos de acordo com a drenagem do lençol freático, através das fraturas das rochas, dos poros existentes entre os sedimentos e pelas redes de pipes.

Aplicando a Equação (1) na bacia $\mathbf{A}$, obtiveram-se os seguintes resultados. Do vertedouro 1 ao vertedouro 2 (segmento de canal b), a distância é de $60 \mathrm{~m}$, e a taxa média de crescimento foi 0,0095 litro por metro de canal por segundo $(1 / \mathrm{m} / \mathrm{s})$. Porém, a maior área contribuinte está no segmento de calha $c$, com uma taxa média de $0,0731 \mathrm{l} / \mathrm{m} / \mathrm{s}$. Esse trecho possui $20 \mathrm{~m}$ e é alimentado por uma subunidade de encosta do tipo hollow e a contribuição dos fluxos subsuperficiais representaram em média, $52 \%$ da descarga total da bacia (Tabela 1 - Figura 2).

$\mathrm{Na}$ bacia A, o canal possui $420 \mathrm{~m}$ de extensão e a nascente principal é do tipo móvel (Faria, 1997). O canal perene possui $130 \mathrm{~m}$ e o trecho final intermitente possui $290 \mathrm{~m}$, isto ocorre porque a nascente pode migrar dentro da calha numa extensão de até $290 \mathrm{~m}$, de acordo com a oscilação do nível do lençol freático. O vertedouro 3 foi instalado a $140 \mathrm{~m}$ da foz (dez metros acima do limite entre os segmentos de calha perene e intermitente), assim, a distância entre a nascente e esse vertedouro pode variar de zero a $280 \mathrm{~m}$. A taxa de crescimento do fluxo de base nesse trecho variou de zero a $0,0351 \mathrm{l} / \mathrm{m} / \mathrm{s}$.

Tabela 1. Crescimento do fluxo da bacia $A$.

\begin{tabular}{|c|c|c|c|c|}
\hline $\begin{array}{l}\text { Segmentos } \\
\text { de calha }(\mathrm{m})\end{array}$ & $\begin{array}{c}\mathrm{L} \\
(\mathrm{m})\end{array}$ & $\begin{array}{l}\mathrm{Qm} \\
(\mathrm{l} / \mathrm{s})\end{array}$ & $\begin{array}{c}\mathrm{TxC} \\
(\mathrm{l} / \mathrm{m} / \mathrm{s})\end{array}$ & $\begin{array}{c}\mathrm{C} \\
(\%)\end{array}$ \\
\hline a foz-60 & 60 & - & - & 5 \\
\hline b $\quad 60-120$ & 60 & 0,569 & 0,0095 & 20 \\
\hline c $120-140$ & 20 & 1,462 & 0,0731 & 52 \\
\hline d $140-130^{*}$ & $s / f$ & $s / f$ & $s / f$ & 0 \\
\hline $140-420^{*}$ & 280 & 0,676 & 0,0351 & 23 \\
\hline
\end{tabular}

* O comprimento total do canal da bacia A é de $420 \mathrm{~m}$, mas a posição da nascente dentro da calha migra cerca de $290 \mathrm{~m}$ (130 - $420 \mathrm{~m})$

Nas Tabelas 1, 2 e 3, L significa o comprimento do segmento de calha entre os vertedouros; $\mathbf{Q m}$ é a vazão média afluente a cada trecho (vazão de jusante - vazão de montante); TxC significa a taxa de contribui- 
ção de água para o canal; C é a contribuição de cada segmento em porcentagem; s/f significa calha sem fluxo.

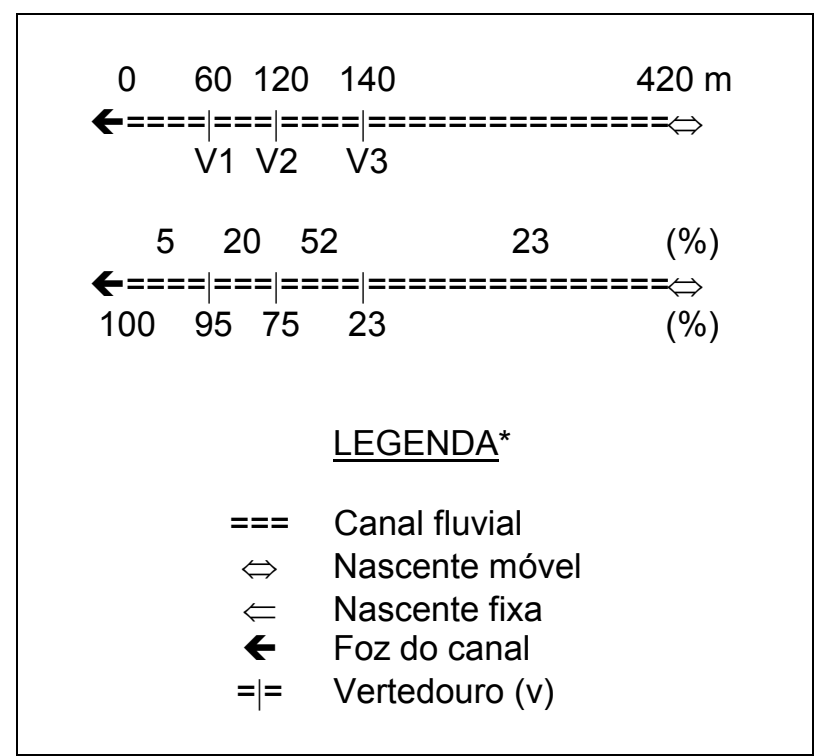

* A legenda da Figura 2 serve também para as Figuras 3 e 4.

Figura 2. Crescimento do fluxo (\%) - bacia A.

Na bacia B a nascente principal também é do tipo móvel e pode migrar em até $230 \mathrm{~m}$ ao longo da calha. O canal de $250 \mathrm{~m}$ de comprimento é dividido em segmentos perene $(20 \mathrm{~m})$ e intermitente $(230 \mathrm{~m})$. Essa bacia possui três áreas contribuidoras principais, que alimentam a maior parte do fluxo de base.

Uma dessas áreas fonte é uma subunidade de encosta formada por spur e se localiza na encosta esquerda, onde os fluxos aparecem de pipes e na matriz do solo, entre o vertedouro 1 e o vertedouro 2 (segmento de canal $b$ ), com distância de $15 \mathrm{~m}$ entre os dois. A taxa média de crescimento do fluxo foi de $0,0466 \mathrm{l} / \mathrm{m} / \mathrm{s}$. Outra área fonte também é formada por pipes e fluxos pela matriz do solo, estando situada em uma subunidade de spur, na encosta direita, no segmento de calha $c$, com distância de $42 \mathrm{~m}$. A taxa de crescimento do fluxo nesse trecho é de $0,0195 \mathrm{l} / \mathrm{m} / \mathrm{s}$. Um único pipe nessa área (pipe B3) contribuiu com uma média de $18 \%$ da descarga total relativa ao fluxo de base da bacia $\mathbf{B}$, e esse trecho contribuiu em média com $49 \%$ para o fluxo do canal. De acordo com Faria (1997), este pipe é uma nascente secundária do tipo fixa.

A terceira área fonte é formada por um hollow, que é uma subunidade da encosta esquerda da bacia, onde a água escoa de pipes e através da matriz do solo. Essa área situa-se entre o vertedouro 3 e a nascente móvel (segmento de canal $d$ ), e a taxa de crescimento do fluxo variou de zero a $0,0426 \mathrm{l} / \mathrm{m} / \mathrm{s}$, dependendo da posição da nascente dentro da calha (Tabela 2 - Figura 3).

Tabela 2. Crescimento do fluxo da bacia B.

\begin{tabular}{llcccr}
\hline $\begin{array}{l}\text { Segmentos } \\
\text { de calha }(\mathrm{m})\end{array}$ & $\begin{array}{c}\mathrm{L} \\
(\mathrm{m})\end{array}$ & $\begin{array}{c}\text { Qm } \\
(\mathrm{I} / \mathrm{s})\end{array}$ & $\begin{array}{c}\text { TxC } \\
(\mathrm{I} / \mathrm{m} / \mathrm{s})\end{array}$ & $\begin{array}{c}\mathrm{C} \\
(\%)\end{array}$ \\
\hline a & foz-5 & 5 & - & - & 1 \\
$\mathrm{~b}$ & $5-20$ & 15 & 0,669 & 0,0466 & 40 \\
$\mathrm{c}$ & $20-62$ & 42 & 0,819 & 0,0195 & 48 \\
$\mathrm{~d}$ & $62-20^{*}$ & $\mathrm{~s} / \mathrm{f}$ & $\mathrm{s} / \mathrm{f}$ & $\mathrm{s} / \mathrm{f}$ & 0 \\
& $62-250^{*}$ & 188 & 0,183 & 0,0246 & 11 \\
\hline
\end{tabular}

* O comprimento total do canal da Bacia B é de $250 \mathrm{~m}$ e a nascente migra cerca de $230 \mathrm{~m}$ (20-250 m).

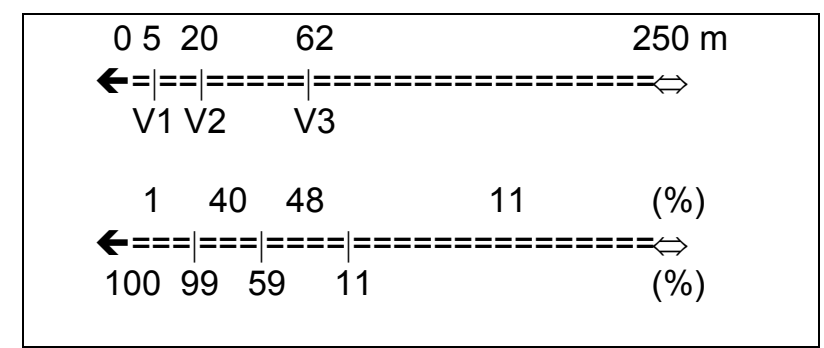

Figura 3. Crescimento do fluxo (\%) - bacia B.

A bacia C possui um canal de $470 \mathrm{~m}$ de comprimento e a nascente principal é do tipo fixa, isto é, de acordo com Faria (1997), ela não migra de posição o que significa que todo o canal é perene e também existem várias nascentes secundárias formadas por pipes.

No segmento de canal $b$, com $20 \mathrm{~m}$ de comprimento, a contribuição foi de cerca de $20 \%$ da descarga total, com uma vazão de $0,0353 \mathrm{l} / \mathrm{m} / \mathrm{s}$. O segmento de calha e, com $10 \mathrm{~m}$ de comprimento, recebeu $13 \%$ da descarga total, com uma taxa de $0,0458 \mathrm{l} / \mathrm{m} / \mathrm{s}$.

O fluxo entre a nascente e o vertedouro 6 (segmentos $g$ e $h$ ) carregou apenas $22 \%$ da descarga total da bacia, mas esse trecho possui $246 \mathrm{~m}$, o que é mais da metade do 
comprimento do canal, e a maior parte desse volume se origina diretamente na nascente; entretanto, para fins de cálculo, a taxa de crescimento do fluxo foi de $0,0035 \mathrm{l} / \mathrm{m} / \mathrm{s}$ no segmento $h$, com $112 \mathrm{~m}$ de comprimento e no segmento $g$ com $134 \mathrm{~m}$ de extensão -, a taxa foi de $0,0029 \mathrm{l} / \mathrm{m} / \mathrm{s}$ (Tabela 3 - Figura 4 ).

Tabela 3. Crescimento do fluxo da bacia C.

\begin{tabular}{llrccc}
\hline $\begin{array}{l}\text { Segmentos } \\
\text { de calha }(\mathrm{m})\end{array}$ & $\begin{array}{c}\mathrm{L} \\
(\mathrm{m})\end{array}$ & $\begin{array}{c}\text { Qm } \\
(\mathrm{l} / \mathrm{s})\end{array}$ & $\begin{array}{c}\text { TxC } \\
(\mathrm{l} / \mathrm{m} / \mathrm{s})\end{array}$ & $\begin{array}{c}\mathrm{C} \\
(\%)\end{array}$ \\
\hline a & foz-3 & 3 & - & - & - \\
$\mathrm{b}$ & $3-23$ & 20 & 0,706 & 0,0353 & 20 \\
$\mathrm{C}$ & $23-33$ & 10 & 0,352 & 0,0352 & 10 \\
d & $33-188$ & 155 & 0,707 & 0,0045 & 20 \\
e & $188-198$ & 10 & 0,458 & 0,0458 & 13 \\
$\mathrm{f}$ & $198-225$ & 27 & 0,529 & 0,0195 & 15 \\
$\mathrm{~g}$ & $225-359$ & 134 & 0,388 & 0,0029 & 11 \\
$\mathrm{~h}$ & $359-470$ & 112 & 0,388 & 0,0035 & 11 \\
\hline
\end{tabular}

O comprimento total do canal da Bacia C é de $470 \mathrm{~m}$ e a nascente é do tipo fixa (todo o canal é perene).

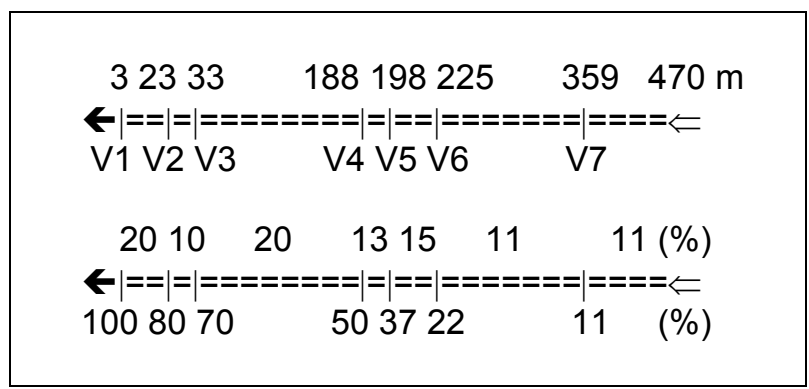

Figura 4. Crescimento do fluxo (\%) - bacia C.

A taxa de crescimento do fluxo nos canais das microbacias varia muito no espaço e no tempo e depende das áreas de maior ou menor concentração de fluxos subsuperficiais, o que pode variar de 0,0095 a 0,0731 l/m/s. A variação temporal vai depender do volume de água estocado no lençol freático. Por exemplo, na bacia $\mathbf{A}$, a taxa de crescimento do volume do fluxo entre os vertedouros 1 e 2 pode variar de $0,0007 \mathrm{l} / \mathrm{m} / \mathrm{s}$ (registrado em 11/04/94), a $0,0248 \mathrm{l} / \mathrm{m} / \mathrm{s}$ (em 01/12/95), lembrando que os resultados divulgados nas Tabelas 1,2 e 3 são valores médios. A taxa de crescimento dos fluxos nos canais intermitentes, quando estes estão secos, é considerada como zero, mas quando o nível do lençol freático sobe e forma fluxo, a taxa pode ser de até $0,0351 \mathrm{l} / \mathrm{m} / \mathrm{s}$ na bacia A e $0,0246 \mathrm{l} / \mathrm{m} / \mathrm{s}$ na bacia B. Anderson e Burt (1978) postulam que, nas pequenas bacias, cujas vertentes são formadas por subunidades de hollow e spur, o canal recebe maior contribuição de água dos hollows, por serem áreas de convergência de fluxos subsuperficiais e superficiais. Porém, algumas bacias são complexas, redes de pipes e pseudopipes e a descontinuidade na espessura do aqüífero podem complicar este modelo. No Maciço da Tijuca, muitos pipes formam nascentes secundárias e aparecem nas subunidades de encostas formadas por spur (zonas de divergência de água); a contribuição deles para o fluxo de base em algumas áreas é maior que nas subunidades formadas pelos hollows.

Durante os períodos de estiagem prolongada, ocorreram algumas mudanças significativas nas bacias estudadas. A extensão do fluxo dentro da calha da bacia $\mathbf{A}$ ficou reduzida em até $46 \%$ do tamanho máximo médio. O comprimento médio no trimestre mais úmido (Jan/Fev, 1996) era de $248 \mathrm{~m}$ e antes, no trimestre mais seco (Abr/Jun, 1995) era de $134 \mathrm{~m}$; na bacia $\mathbf{B}$, no período mais úmido o comprimento médio era de $182 \mathrm{~m}$ e no mais seco ficou em $20 \mathrm{~m}$ (redução de $88 \%$ ). Na bacia $\mathbf{C}$ não há redução no comprimento do fluxo, porque a nascente não migra, mas a vazão oscila muito, como em todas as outras bacias. Nesta bacia, a vazão relativa ao fluxo de base varia de 1,1 a $16,0 \mathrm{l} / \mathrm{s}$. A Tabela 4 mostra comparativamente esses dados, porém, considerando os valores médios.

As chuvas torrenciais prolongadas e de alta intensidade causaram aumentos na vazão dos canais dessas bacias em até 400 vezes, em relação às descargas regulares relativas ao fluxo de base. Nos dias 13 e 14 de fevereiro de 1996 (precipitação de $378 \mathrm{~mm} / 48 \mathrm{~h}$ ), a vazão do fluxo da bacia $\mathbf{A}$ foi estimada em $900 \mathrm{l} / \mathrm{s}$, mas regularmente esse fluxo é de pouco mais de $2 \mathrm{l} / \mathrm{s}$; a bacia $\mathbf{B}$ teve um fluxo estimado em $540 \mathrm{l} / \mathrm{s}$ e a bacia $\mathbf{C}$ a descarga foi estimada em $800 \mathrm{l} / \mathrm{s}$. Esses volumes adicionais de água são relativos aos escoamentos provenientes da superfície das encostas (overlandflow) e dos fluxos de chuva (inter- 
flow) que infiltram nos macroporos e são drenados rapidamente para os canais fluviais.

Tabela 4. Efeitos com a variação de umidade.

\begin{tabular}{|c|c|c|c|}
\hline $\begin{array}{l}\text { Bacias } \\
\text { Área das bacias (ha) }\end{array}$ & $\begin{array}{r}A \\
14\end{array}$ & $\begin{array}{l}\text { B } \\
6\end{array}$ & $\begin{array}{l}\mathbf{C} \\
11\end{array}$ \\
\hline \multicolumn{4}{|c|}{ Trimestre mais Seco 386 mm (Abr/Jun-1995) } \\
\hline Extensão do fluxo (m) & 134 & 23 & 470 \\
\hline$Q$ média da bacia $(\mathrm{l} / \mathrm{s})$ & 0,3 & 0,2 & 1,8 \\
\hline \multicolumn{4}{|c|}{ Trimestre mais Úmido 1.387 mm (Jan/Fev-1996) } \\
\hline Extensão do fluxo (m) & 248 & 182 & 470 \\
\hline$Q$ média da bacia (l/s) & 6,5 & 3,8 & 5,8 \\
\hline
\end{tabular}

\section{A contribuição dos pipes para a vazão dos canais}

Os pipes podem ser efêmeros, intermitentes ou perenes, dependendo da profundidade em que se encontram, como também da posição em que se formam no fundo do vale. Se for nos canais efêmeros, eles só podem ser pipes efêmeros; caso seja no segmento intermitente, os pipes podem ser efêmeros ou intermitentes, e se for no segmento perene, eles poderão ser dos três tipos.

Os pipes efêmeros possuem fluxos durante ou logo após as chuvas de alta intensidade e drenam com rapidez a água da chuva que infiltra no solo, formando os fluxos de chuva (quickflow), responsáveis pelas cheias rápidas e torrenciais nos canais. Desta forma, esses pipes possuem um importante papel na hidrologia do solo, evitando a formação de fluxos superficiais sobre as encostas. Devido ao fluxo efêmero, esses pipes são mais difíceis de serem observados e, neste trabalho, eles não foram mapeados e nem monitorados.

Os pipes intermitentes são mais fáceis de serem observados e monitorados, porque possuem vazões durante os períodos úmidos, e alguns mantêm vazões mesmo durante os períodos de estiagem, secando apenas nos períodos de estiagem prolongada. Somente na bacia B, foram contados 98 pipes intermitentes, que mantiveram vazões por mais de duas semanas, após as chuvas de 13 e 14 de fevereiro de 1996 que somaram 378 mm. Porém, como não foi possível monitorar todos, foram escolhidos os mais importantes, que mantém vazões na maior parte do ano. Nas bacias A, B e C eles são ao todo 14. Esses pipes variam muito em tamanho (de 4 a 150 mm de diâmetro) e em comportamento.

Os pipes perenes ocorrem em menor número e foram localizados apenas 6 nas bacias em estudo. Alguns possuem vazões constantes ao longo do ano: pipes B1, B10 e B11 situados na bacia B e C1, localizado na bacia $\mathbf{C}$. Outros possuem vazões que oscilam muito, como o pipe C7 (Tabela 5).

A contribuição dos pipes para a vazão dos canais é significativa; por exemplo, na bacia $\mathbf{B}$, os pipes intermitentes e perenes podem contribuir com mais de $58 \%$ do volume total do fluxo, como foi calculado no período de 02 a 09 de novembro de 1995, quando os pipes B1, B3, B4, B10 e B11 tinham vazões de $0.5,0.5,0.2,0.1$ e $0.3 \mathrm{l} / \mathrm{s}$, respectivamente, totalizando $1,6 \mathrm{l} / \mathrm{s}$ e a vazão da bacia neste período era de $2,7 \mathrm{l} / \mathrm{s}$. Somente o pipe B3 contribuiu em média com $18 \%$ para a vazão da bacia $\mathbf{B}$, e o pipe $\mathrm{A} 6$ contribuiu em média com $10 \%$ para a descarga da bacia A. A Tabela 5 mostra a contribuição dos pipes A6, B3 e C7 para a vazão das suas respectivas bacias. $\boldsymbol{Q}$ significa vazão.

$\mathrm{Na}$ época, não foi feito o mesmo estudo sobre a contribuição total dos pipes para a vazão dos canais das bacias $\mathbf{A}$ e $\mathbf{C}$, devido às dificuldades encontradas no campo.

Tabela 5. Contribuição dos principais pipes para a vazão das bacias.

\begin{tabular}{lrrr}
\hline & $\begin{array}{c}\text { Pipe } \\
\text { A6 }\end{array}$ & \multicolumn{1}{c}{$\begin{array}{c}\text { Pipe } \\
\text { B3 }\end{array}$} & \multicolumn{1}{c}{$\begin{array}{c}\text { Pipe } \\
\text { C7 }\end{array}$} \\
\hline Q mín. bacia (I/s) & 0,696 & 0,243 & 1,428 \\
Q máx. bacia (I/s) & 14,707 & 10,067 & 16,000 \\
Q mín. pipe (I/s) & s/fluxo & 0,130 & 0,048 \\
Q máx. pipe (I/s) & 0,750 & 0,526 & 0,257 \\
Q med. pipe (I/s) & 0,295 & 0,250 & 0,130 \\
Contrib.pipe (\%) & 10 & 18 & 03 \\
\hline
\end{tabular}

Uma grande extensão dos canais seca durante os períodos prolongados de estiagem e ocorre a deposição de material orgânico dentro das calhas, como folhas e galhos. Os pipes que ficam nessa zona (segmento de 
calha intermitente) não apresentam fluxos e os que se desenvolvem dentro dos segmentos de calha perene, secam ou têm as vazões reduzidas. Por exemplo, a vazão do pipe A6 diminuiu de 0,750 para $0,285 \mathrm{l} / \mathrm{s}$ (redução de $62 \%$ ); o pipe B3, passou de 0,526 para $0,130 \mathrm{l} / \mathrm{s}$ (redução de $76 \%$ ) e a vazão do pipe C7, diminuiu de 0,257 para $0,048 \mathrm{l} / \mathrm{s}$ (redução de $82 \%)$.

\section{OUTRAS CONSIDERAÇÕES}

Às vezes, os pipes formam temporariamente as nascentes principais dos canais das bacias A e B. Na bacia A, quando o fluxo na calha atinge o comprimento de $248 \mathrm{~m}$, a nascente principal passa a ser formada pelo pipe intermitente $A 7$ de $10 \mathrm{~cm}$ de diâmetro, com fluxo de até $0,5 \mathrm{l} / \mathrm{s}$. Na bacia B, durante os períodos prolongados de estiagem, quando o fluxo na calha regride para $30 \mathrm{~m}$ de comprimento, o pipe $\mathrm{B} 3 \mathrm{com} 6 \mathrm{~cm}$ de diâmetro, passa a formar a principal fonte de água do canal fluvial, com uma contribuição de até $32 \%$ em relação à vazão total do canal.

Os pipes perenes e intermitentes monitorados no Maciço da Tijuca possuem comportamentos próprios, completamente distintos uns dos outros, em termos de vazão, na oscilação da vazão e no tipo de fluxo (perene ou intermitente). Isto se deve à localização deles em camadas distintas de colúvio e também nos depósitos de tálus, porque essas camadas possuem, além de outras características, granulometria, porosidade e transmissividade hidráulica diferentes, o que pode determinar os seus comportamentos.

$\mathrm{Na}$ área de estudo, principalmente na bacia $\mathbf{C}$, existem pseudopipes que podem ser confundidos facilmente com os pipes verdadeiros. Eles são formados quando o canal fluvial se desenvolve paralelo às diáclases que seguem as estruturas das rochas gnaissicas. Parte da água dos canais é drenada para essas fendas e ressurge à jusante, em um ou mais buracos, localizados nas bordas das caIhas e encostas dos vales. Situação semelhante ocorre quando o fundo das calhas fica no mesmo nível das camadas de sedimentos onde se concentram fragmentos de rocha. Entre seixos, calhaus e matacões, formam-se grandes espaços vazios, que podem evoluir, formando túneis paralelos aos canais, por onde o fluxo entra e reaparece na saída do túnel, na confluência com o canal à jusante, mas um pouco acima do nível da água no canal.

Em alguns canais existem muitas irregularidades no perfil longitudinal, como rupturas de declive e também podem existir diferentes tipos de depósitos sedimentares ou rochas, que podem alterar a dinâmica dos fluxos. Durante os períodos de estiagem, os fluxos nas calhas podem se tornar descontínuos, ou seja, eles aparecem e desaparecem sucessivamente, formando, de acordo com Faria (1997), as pseudonascentes, mas nesse caso, não ocorre a diminuição do volume do fluxo na direção da foz (jusante).

Nos canais das microbacias de áreas semi-áridas (algumas áreas do nordeste brasileiro), pode não ocorrer o aumento cumulativo do volume do fluxo de água na direção de jusante; ao contrário, o fluxo pode diminuir a partir de um ponto, devido à perda de água por infiltração do canal para o lençol freático (perda por transmissividade), que se situa muito abaixo do fundo do canal, e muitas vezes o fluxo na calha pode desaparecer antes de chegar à foz. Essa dinâmica é própria dos canais efêmeros, principalmente nas áreas semi-áridas, de acordo com Thornes (1977), mas também ocorre nos canais intermitentes.

Jones e Crane (1984) em estudos realizados em uma bacia de $1^{\text {a }}$ ordem em Wales (Inglaterra), mostram que a rede de pipes contribui com cerca de $46 \%$ do volume total de água para os fluxos da bacia. Os resultados obtidos neste trabalho indicam que a rede de pipes em um ambiente como na Floresta da Tijuca, pode contribuir com até $58 \%$ (bacia B). Não se pode, em princípio, fazer considerações sobre a diferença existente entre as distintas contribuições, porque existem microbacias muito diferentes uma das outras numa mesma área, inclusive com redes de pipes com características diferentes (diâmetro, extensão e quantidade). Mas será que em solos tropicais existiria um número maior de pipes? ou será que isso poderia ser explicado pela 
direrença entre os ambientes tropicais e temperados? Neste caso, pode-se levar em conta as diferenças nas caracteríticas da pluviosidade, da temperatura, do tipo de solo, da granulometria, da porosidade, da vegetação e da fauna. De qualquer forma, é sempre importante salientar que os ambientes tropicais são muito diferentes dos ambientes temperados e existe um grande perigo na aplicação de modelos importados de ambientes diferentes.

\section{CONCLUSÕES}

No conjunto, os pipes formam um importante fator na dinâmica dos canais de $1^{\text {a }}$ ordem, e a destruição deles, nas áreas que sofrem desmatamentos e compactação dos solos, pode afetar seriamente o comportamento desses canais.

O cálculo da taxa de crescimento do volume do fluxo em direção de jusante pode ser muito importante no plano de manejo de microbacias, porque através dele pode-se identificar as áreas que mais contribuem para os fluxos das microbacias e, portanto, as mais sensíveis, as quais merecem atenção especial.

Os resultados obtidos mostram que em geral, da nascente até a metade da extensão do canal, a alimentação de água é de apenas $20 \%$ do total do volume do fluxo e os $80 \%$ restantes são gerados na última metade. Isso mostra a fragilidade das nascentes e áreas próximas, devido ao reduzido volume de vazão.

A taxa de crescimento do fluxo espacializa a contribuição de uma determinada área em um certo trecho do canal. Mas deve-se tomar cuidado porque a verdadeira contribuição pode vir, por exemplo, de um ponto como um pipe e esse fluxo é dividido por vários metros. Para diminuir a margem de erro, é preciso localizar e mapear os pipes e instalar uma quantidade máxima possível de vertedouros nas calhas, para identificar as áreas de maior contribuição de água para os fluxos dos canais.

Os dados apresentados neste trabalho são referentes às bacias situadas em área montanhosa florestada de clima tropical úmi- do. Tais resultados podem não ser compatíveis com microbacias que sofrem outros tipos de uso e microbacias situadas em outros tipos de clima.

\section{REFERÊNCIAS}

ANDERSON, M. G and BURT, T. P. 1978, The role of topography in controling throughflow generation. Earth Surface Processes, 3: 331344.

BEVEN, K and GEMANN, P. 1982, Macropores and water flow in soils. Water Resource Research, 18 (5): 1311-1325.

BIGARELLA, J. J. e MAZUCHOWSKI, J. 1985, Visão Integrada da Problemática da Erosão. Curitiba. Associação Bras. Geologia de Engenharia, $332 \mathrm{p}$.

CASTRO JÚNIOR, E. 1991, O Papel da Fauna Endopedônica na Estruturação Física do Solo e Seu Significado para a Hidrologia de Superfície. Tese de Mestrado, IGEO-UFRJ, 150p.

FARIA, A. P. 1996a, Dinâmica e Fragilidade das Bacias Fluviais de Primeira Ordem. Tese de Doutoramento, IGEO-UFRJ, $218 \mathrm{p}$.

FARIA, A. P. 1996b, Oscilação na extensão da rede de drenagem em fases de desmatamento e reflorestamento. Sociedade e Natureza (I Simpósio Nacional de Geomorfologia), 15: 5155.

FARIA, A. P. 1997, A dinâmica de nascentes e a influência sobre os fluxos nos canais. A Água em Revista (CPRM), 8:74-80.

JONES, A. 1971, Soil piping and stream channel initiation. Water Resource Research, 7 (3): 602-610.

JONES, J. A. A. and CRANE F. G. 1984, Pipeflow and pipe erosion in the Maesnant experimental catchment. In T. P. Burt and D. E. Walling (ed). Catchment Experiments in Fluvial Geomorphology. GeoBooks, pp 55-72.

McCAIG, M. 1983, Contributions to storm quickflow in a small headwater catchment: the role of natural pipes and soil macropores. Earth Surface Processes and Landform, 8: 239-252.

MENDIONDO, E. M. e TUCCI, C. E. M. 1997, Escalas hidrológicas. III: hipótese integradora de processos na bacia vertente. Revista Brasileira de Recursos Hídricos, 2 (1): 101122.

PEARCE, A. J.; STEWART, M. K., and SKLASH, M. G. 1986, Storm runoff generation in humid headwater catchments 1 . Where does the 
water come from? Water Resource Research, $22(8), 1263-1272$.

STRAHLER, A. A. 1952, Hypsometric (areaaltitude) analysis of erosional topography. Geol. Soc. America Bull. 63: 1117-1142.

SHREEVE, R. L. 1966, Statical law of stream number. Journal of Geology, 74 (1): 17-37.

THORNES, J. B. 1977, Channel changes in ephemeral streams: observations, problems, and models. In K. J. Gregory (ed) Channel Changes: p. 317-335.

TSUKAMOTO, Y. 1987, Hydrogeomorphological characteristics of a zero order basin. $A$ Collection of Reprints. Tokyo, Department of Forestry, University of Agriculture and Technology (unpuplished paper)

\section{The Importance of Pipes in the Feeding and Behavior of Small Fluvial Channels}

ABSTRACT

First order channels have many singular characteristics. For instance, its start in springs and the flow increases as it moves downstream. At the end of the channel the runoff is considered to be $100 \%$, however, this may vary according to the morphology of the subunits of the slope and some features of the aquifer, like storage capacity and the formation of the pipe network. Research has been done on three first order basins situated in Floresta da Tijuca (Rio de Janeiro city) to investigate the dynamic of the channel as the flow increases downstream and the role of natural pipes in feeding the streams. The results show that near the spring the contribution of water is very little, in fact, only $20 \%$ of the total volume in runoff can be found in the area between the spring and half of the channel length. The second half of the channel receives $80 \%$ of the runoff. Sometimes during the wet season the pipe network can contribute $58 \%$ of the total stream volume and in a dry period $32 \%$ may come from a single pipe illustrating the importance of pipes upon the dynamic of small channels and the fragility of upstream areas of first order basins. 